\title{
Desafios da assistência de enfermagem aos indivíduos vítimas de violência por armas de fogo e branca
}

\author{
Challenges of nursing assistance to individuals victims of violence by firearms and white \\ weapons
}

Retos de la asistencia de enfermería a personas víctimas de violencia por armas de fuego y armas blancas

Josiane Palavro Barros ${ }^{1 *}$, Aline Silva dos Santos Dapper ${ }^{1}$, Kelly Ribeiro de Freitas Viana ${ }^{2}$, Márcia Dornelles Machado Mariot ${ }^{2}$, Dayane de Aguiar Cicolella ${ }^{2}$.

\section{RESUMO}

Objetivo: Conhecer os principais desafios enfrentados por profissionais de enfermagem que realizam assistência e cuidados aos indivíduos vítimas de violência por armas de fogo e arma branca. Métodos: Tratase de um estudo qualitativo, descritivo exploratório. A pesquisa foi realizada em uma unidade de internação de um hospital geral da rede pública, localizado em uma cidade do RS. A coleta de dados deu-se através de entrevistas abertas, gravadas em áudio, guiadas por instrumento facilitador e posteriormente transcritas. Os dados foram analisados através da análise temática de Minayo MCS (2014) em três etapas: pré-análise; exploração do material; tratamento dos resultados obtidos e interpretação. Resultados: Observou-se que os principais desafios que os profissionais enfrentam durante a assistência às vítimas de violência são o estresse laboral, medo de sofrer alguma violência e o senso de justiça versus o cuidado humanizado. Conclusão: Diante dos fatos, faz-se necessário à criação e implementação de políticas e estratégias a fim de prevenir situações de violência e melhorar as condições trabalhistas. Ressaltando que estas melhorias terão reflexo positivo na assistência prestada.

Palavras-chave: Violência, Saúde mental, Profissionais de enfermagem.

\begin{abstract}
Objective: To know the main challenges faced by nursing professionals who provide assistance and care to individuals victims of violence by firearms and bladed weapons. Methods: This is a qualitative, descriptive exploratory study. The research was carried out in an inpatient unit of a general public hospital, located in a city in RS. Data collection took place through open interviews, recorded on audio, guided by a facilitating instrument and later transcribed. The data were analyzed through the thematic analysis by Minayo MCS (2014) in three stages: pre-analysis; exploration of the material; treatment of the results obtained and interpretation. Results: It was observed that the main challenges that professionals face when assisting victims of violence are job stress, fear of suffering some violence and a sense of justice versus humanized care. Conclusion: Given the facts, it is necessary to create and implement policies and strategies in order to prevent situations of violence and improve working conditions. Emphasizing that these improvements will have a positive impact on the assistance provided.
\end{abstract}

Keyword: Violence, Mental health, Nursing professionals.

1 Universidade Inedi-Cesuca, Cachoeirinha - RS. *E-mail: josipalavro@hotmail.com

2 Universidade Federal do Rio Grande do Sul, Porto Alegre - RS.

SUBMETIDO EM: $8 / 2020$

ACEITO EM: 9/2020

PUBLICADO EM: 12/2020

REAS/EJCH | Vol.12(12) | e5045 | DOI: https://doi.org/10.25248/reas.e5045.2020 Página 1 de 8 


\section{RESUMEN}

Objetivo: Conocer los principales desafíos que enfrentan los profesionales de enfermería que brindan asistencia y atención a las personas víctimas de violencia por armas de fuego y armas blancas. Métodos: Se trata de un estudio exploratorio descriptivo, cualitativo. La investigación se llevó a cabo en una unidad de internación de un hospital público general, ubicado en una ciudad de RS. La recolección de datos se realizó mediante entrevistas abiertas, grabadas en audio, guiadas por un instrumento facilitador y posteriormente transcritas. Los datos fueron analizados mediante el análisis temático de Minayo MCS (2014) en tres etapas: preanálisis; exploración del material; tratamiento de los resultados obtenidos e interpretación. Resultados: Se observó que los principales desafíos que enfrentan los profesionales en la atención a víctimas de violencia son el estrés laboral, el miedo a sufrir alguna violencia y el sentido de justicia versus atención humanizada. Conclusión: Ante los hechos, es necesario crear e implementar políticas y estrategias para prevenir situaciones de violencia y mejorar las condiciones laborales. Destacando que estas mejoras tendrán un impacto positivo en la asistencia brindada.

Palabras clave: Violencia, Salud mental, Profesionales de enfermería.

\section{INTRODUÇÃO}

Atualmente considera-se a violência como sendo um grande problema social e de saúde pública. A ocorrência da mesma no ambiente de trabalho é definida como violência laboral e engloba qualquer incidente onde os profissionais sofram ameaças, abusos ou agressões tanto de natureza física, moral ou psicológica, desencadeados por colegas de profissão, empregadores, clientes, pacientes ou acompanhantes (FERREIRA MJM, et al., 2017).

No Brasil, tal problema necessita ser estudado mais profundamente, uma vez que sua magnitude é subestimada pela invisibilidade das ocorrências e suas consequências, o que contribui para que as agressões sejam tratadas como 'naturais' em muitos ambientes laborais. No âmbito hospitalar a classe profissional mais atingida por este tipo de violência é a da enfermagem. $E$ a forma mais frequente, neste caso, é a violência verbal. Isso se deve pelo fato do contato direto entre funcionários e pacientes durante os cuidados prestados.

Muitas vezes, devido à precariedade do sistema de saúde, esse atendimento acaba sendo conflituoso e isso contribui para que usuários e/ou acompanhantes tenham atitudes violentas perante a equipe profissional (VASCONCELLOS IRR, et al., 2012a).

Hoje em dia o número de internações hospitalares de vítimas de violência por ferimento com arma branca (FAB) como facas, punhais, canivetes e de arma de fogo (FAF) aumentam consideravelmente a cada ano e ocupam posição de destaque no perfil de mortalidade. Trata-se de um importante problema de saúde pública, pois as vítimas de violência por tais ferimentos são a 3ำ causa no Brasil, antecedido apenas pelas doenças do aparelho circulatório e cânceres (ABREU FS, et al., 2014; MACIEL OS, et al., 2016).

Tais lesões muitas vezes causam danos irreversíveis e incapacitantes ao indivíduo além de gerar altos custos para o Sistema Único de Saúde (SUS), para a Previdência Social e para suas famílias, por necessitarem dos mais diversos tipos de cuidados (RIBEIRO AP, et al., 2017; IPEA, 2018).

O ambiente de trabalho, enquanto espaço social é diretamente afetado pelo crescimento da violência. Geralmente, os hospitais não possuem unidades de internações específicas para atendimento a este perfil de vítimas de violências e esse fato acaba gerando certo desconforto tanto para a equipe multiprofissional quanto ao cliente em questão.

Devemos ressaltar que, dentro de uma mesma instituição hospitalar há inúmeros setores com profissionais exercendo diversas atribuições e responsabilidades específicas; consequentemente, haverá exigências internas e externas de várias complexidades e intensidades que podem desencadear diferentes níveis de ansiedade e estresse em seus colaboradores (VASCONCELLOS IRR, 2012b). 
Um dos profissionais de maior presença na assistência do cuidado é o enfermeiro. Geralmente é ele que tem o primeiro contato com as vítimas de violência e este fato colabora para que haja o aumento do vínculo da relação/interação entre ambos, facilitando a obtenção de informações que outros membros da equipe de saúde não têm acesso por não ficarem tão próximos e por tanto tempo (ÁVILA J, et al., 2012; TAPIA CLV, et al., 2014).

No entanto, em alguns casos, a equipe de enfermagem pode obter menor vínculo com pacientes vítimas de $F A F$ ou $F A B$, pois os mesmos algumas vezes não permitem uma maior aproximação, seja por receio de serem "julgados", por vergonha, "pacto de silencio" ou autoproteção. Nesse sentido, isso pode gerar estresse em ambas as partes, consequentemente, a assistência deste indivíduo pode ser prejudicada e deficitária.

A partir da hipótese que profissionais de enfermagem que trabalham com vítimas de violência passam por diferentes situações como estresse, medo, ansiedade entre outros, surge o objetivo desta pesquisa, identificar quais são os principais desafios enfrentados por profissionais de enfermagem que realizam assistência e cuidados aos indivíduos vítimas de violência por armas de fogo e arma branca em uma unidade de internação hospitalar.

\section{MÉTODOS}

Trata-se de um estudo qualitativo, descritivo exploratório. A pesquisa foi realizada em uma unidade de internação de um hospital geral da rede pública, localizado em uma cidade do RS. A população estudada foi constituída de 11 técnicos de enfermagem e 3 enfermeiros. A coleta de dados deu-se através de entrevistas abertas, gravadas em áudio, guiadas por instrumento facilitador e posteriormente transcritas.

Os dados foram analisados através da análise temática de Minayo MCS (2014) em três etapas: préanálise; exploração do material; tratamento dos resultados obtidos e interpretação. A pesquisa seguiu os aspectos éticos e legais, garantindo a confidencialidade dos dados e do participante, respeitando às Diretrizes e Normas Reguladoras de Pesquisas Científicas do Conselho Nacional de Saúde pela Resolução № 466 de 12 de dezembro de 2012.

A pesquisa foi aprovada pela instituição onde ocorreu a coleta de dados e pelo Comitê de Ética em Pesquisa da Faculdade Cesuca em 27 de março de 2020, parecer $n^{\circ}$ CAAE 29800819.7.0000.5665. Todos os participantes assinaram e preencheram o Termo de Consentimento Livre e Esclarecido em duas vias, que assegura a participação livre e espontânea, sem remuneração, desistência em qualquer momento da pesquisa e a confidencialidade dos dados coletados.

As informações obtidas através da pesquisa científica foram utilizadas e analisadas para o desenvolvimento do estudo e o anonimato dos entrevistados foram garantidos. O material coletado será arquivado por 5 anos e após este período o mesmo será inutilizado e descartado.

\section{RESULTADOS}

Após análise das entrevistas, foi possível desenvolver as seguintes categorias temáticas para interpretação dos dados obtidos, sendo elas: estresse laboral no cuidado aos pacientes vítimas de violência por armas; medo de sofrer alguma violência e, por fim, senso de justiça versus cuidado humanizado.

\section{O estresse laboral}

Estresse ocupacional é resultante da forma como o indivíduo lida com as suas atividades laborais e da maneira como realiza o seu enfrentamento. Sendo assim, para suportar circunstâncias estressantes, podem ser utilizadas variadas alternativas de enfrentamento, de maneira a vivenciá-las melhor, evitando uma condição patológica. Neste caso, é importante que os profissionais de saúde reconheçam os agentes estressores do seu ambiente de trabalho (ANDOLHE R, et al., 2015; OLIVEIRA EB, et al., 2017).

Segundo Costa D e Martins M (2011) o ambiente laboral influencia significativamente na saúde de seus colaboradores, uma vez que o nível de estresse atua não somente diminuindo a qualidade do serviço prestado, mas também é o principal agente causador de doenças mentais como ansiedade e depressão. 
Estas patologias acabam gerando prejuízo na qualidade de vida do colaborador que podem levá-lo a insatisfação profissional, baixa autoestima, desinteresse pelo trabalho, problemas de relacionamento com a equipe, altos índices de absenteísmo, incapacitação temporária e os afastamentos por auxílio-doença (KESTENBERG CCF, et al., 2015). Nesta pesquisa percebeu-se que os profissionais estão expostos a diversos fatores estressores relacionados às suas atividades laborais, descritos abaixo:

"Não tem como não ter medo e se estressar. Eles gritam e nos xingam, como se nós tivéssemos culpa de alguma coisa e pelo contrário, estamos aqui ajudando eles. Isso me deixa muito estressada, chateada e irritada porque muitas vezes eles que se colocaram em situação de risco e acabaram no hospital (E2).

"É muito difícil manter a calma e a postura quando os clientes são desaforados e mal intencionados. Outro desafio é eles acharem que nós da enfermagem não somos ninguém, não nos escutam e nem seguem nossas recomendações para um bom andamento do tratamento, acham que só o médico que sabe e isso gera um estresse muito grande na gente" (E10).

Ao se depararem com o contexto descrito acima, os profissionais acabam se desmotivando e, consequentemente, adquirindo sentimento de impotência diante de desigualdades, injustiças e dificuldades, perdendo o prazer pelo trabalho e demais atividades cotidianas, podendo muitas vezes optar pela demissão ou afastamentos, conforme a fala abaixo:

"Confesso que no início foi muito difícil. Não estava acostumada com este tipo de paciente, com as gírias e algumas atitudes desrespeitosas deles. Eu vinha trabalhar por obrigação, sem ânimo nenhum e muitas vezes pensei em pedir demissão. Mas, não é fácil conseguir um bom emprego hoje em dia. Então, eu continuo trabalhando aqui e acabei me acostumando com essa rotina, mas tem muitos colegas que não aguentaram e estão afastados do trabalho" (E4).

Compreende-se o estresse ocupacional como sendo a influência entre alta demanda psicológica, baixo controle sobre o trabalho e o escasso apoio social que o indivíduo recebe dos demais colaboradores e das chefias, ou seja, um local desagradável, tenso e de relações conflituosas. Permanecer ao decorrer do tempo sob estressores laborais e ausência de mecanismos externos e internos que ajudem na adaptação às situações no trabalho acarreta o desgaste crônico e, por sua vez, possível adoecimento deste colaborador (VIDOTTI V, et al., 2019; MASLACH C, 2016).

Nesse sentido, é fundamental que tais profissionais tenham consciência das causas e sintomas do problema para que possam identificar e tratar precocemente possíveis sinais estressores ou patologias, a fim de evitar o adoecimento psíquico decorrente do ambiente de trabalho e, consequentemente, afastamentos das suas atividades laborais.

\section{Medo da violência}

Violência ocupacional é definida segundo a Organização Internacional do Trabalho (2018) como qualquer ação, incidente, comportamento ou atitude instintiva do agressor, em decorrência da qual um profissional é agredido, ameaçado, sofre algum dano ou lesão, durante a realização do seu trabalho. Tais ações têm consequências diversas que nem sempre são visíveis, podendo provocar lesões imediatas ou mais tardias, a nível físico ou psicológico.

Dentre os diversos riscos psicossociais que podem surgir no ambiente laboral, ressalta-se que a violência possui efeito nocivo e pode ocasionar outros problemas que vão igualmente afetar o rendimento e a qualidade da assistência deste profissional e até mesmo, levá-lo ao abandono do trabalho. A categoria mais exposta são os profissionais que atuam diretamente na assistência às vítimas, dentro e fora do hospital como, por exemplo, os enfermeiros (WHO, 2018).

Nesta pesquisa, alguns entrevistados relatam medo de sofrer algum tipo de violência em relação ao perfil da clientela atendida, conforme os trechos das entrevistas abaixo: 
"Teve um dia que o paciente queria agredir a colega. Aí nós chamamos a segurança, mas nos informaram que só tinha um vigilante para o hospital todo e naquele momento ele estava fazendo um atendimento em outro andar. Então, para evitar mais confusão, nós trocamos a colega de escala para que ela não precisasse mais atender ele" (E2).

"Quando fui ameaçada fiquei com muito medo e chorei diversas vezes. Sabemos que a maioria nos ameaça e não faz nada, mas eu ficava pensando: e se esse for diferente e fizer? Meus colegas iam comigo até a parada do ônibus, mas para este tipo de individuo não adiantaria nada e quando fomos prestar queixa na delegacia o policial ficou menosprezando a nossa preocupação, me dando mais raiva de fazer 0 melhor para os meus pacientes e ser tratada com tanta insignificância" (E4).

Uma das maiores preocupações apontadas por estes profissionais de enfermagem são as consequências da estadia desta vítima, pois temem algum tipo de represália de algum grupo que possa tentar resgatá-lo ou até mesmo tentar assassinar a vítima no hospital e de como este indivíduo vai conseguir se auto cuidar após a alta hospitalar. As falas abaixo confirmam tais preocupações:

"certa vez entraram no hospital para "acabar o serviço" e conseguiram. Imagina se eles atiram em algum de nós da equipe ou alguém inocente aqui dentro? Isso nos deixa muito preocupados! Naquela época eu nem dormia mais direito e tinha muito medo de vir pro plantão, cada pessoa que eu encontrava no corredor eu pensava que podia ser alguém suspeito" (E5).

"Em minha opinião o mais difícil é lidar com a insegurança, pelo perfil da grande maioria dos pacientes estarem em confronto com a lei e o risco de estarem no mesmo ambiente que seus "rivais" ou o paciente ser resgatado ou executado na minha frente...e ainda ter equilíbrio emocional para tratar todos como vítimas quando sabemos que muitas vezes não são. Também, tenho dificuldade com o manejo deste paciente, a linguagem que ele utiliza, as gírias... tentar fazer com que ele tenha cuidado com os curativos e a alimentação já que são pessoas muito desregradas. $O$ retorno deles pra sociedade também me preocupa porque a gente sabe que no hospital ele tem acesso à medicação, cuidados e orientação, mas quando ele sai do ambiente hospitalar e retorna pra casa ele não vai manter mais os cuidados e vai ter possivelmente que internar novamente por infecção ou outros problemas" (E14)

A saúde, o bem-estar e a segurança dos profissionais de saúde são assuntos que merecem atenção a nível mundial, uma vez que as exigências emocionais das suas atribuições afetam diretamente a produtividade, a competitividade e a sustentabilidade das organizações (GIMÉNEZ MC, et al., 2019).

Os trabalhadores que sofrem algum tipo de violência sentem-se desvalorizados a ponto de questionar o exercício da profissão e a importância desta para a sua vida. Geralmente, em busca pela autodefesa, tais trabalhadores desenvolvem mecanismos como a hostilidade com pacientes e seus familiares ou, até mesmo, com outros colegas, além da negação e do distanciamento afetivo (SCARAMAL DA, et al., 2017).

O processo de modificação do cuidado intra-hospitalar para o domiciliar modifica a dinâmica e as relações familiares dos indivíduos, pois a responsabilidade do cuidado é transferida parcial ou integralmente para a família, gerando uma sobrecarga física e psicológica aos mesmos (CASTRO EAB, et al., 2018). Quando somente um familiar assume a responsabilidade desta assistência, torna-se ainda mais desgastante, pois geralmente, este é privado de atender as suas próprias necessidades, comprometendo sua saúde, causando afastamentos e danos sociais (MOCELIN C, et al., 2017).

Os profissionais de saúde têm papel fundamental no tratamento do paciente, pois, além de prestarem assistência qualificada, também, são responsáveis por fornecer orientações adequadas e de fácil entendimento ao paciente e seus familiares. Para isso recomenda-se a educação em saúde como uma estratégia para o desenvolvimento de competências e habilidades, ou seja, torná-los, sempre que possível, independentes desta assistência, capacitando-os para o autocuidado após a alta hospitalar. 


\section{Senso de justiça versus cuidado humanizado}

No exercício profissional, a enfermagem se depara com diversas situações que influenciam diretamente no cuidado. Muitas vezes os valores morais adquiridos como ser humano, em algum momento, podem entrar em conflito com os valores impostos pela profissão.

Um dos grandes desafios dos profissionais de saúde na assistência ao indivíduo vítima de violência por arma de fogo é vencer o preconceito e a discriminação para que possam prestar cuidado humanizado, respeitando a vida, a dignidade e os direitos da pessoa em todo seu ciclo vital (COFEN, 2000).

Nas instituições hospitalares muitos são os personagens vítimas das variadas formas de violência: a mulher espancada pelo companheiro; a criança vitimizada pelos pais; o adolescente que reagiu ao assaltado; o assaltante; o suspeito capturado por policiais; aquele indivíduo que sofreu algum 'ajuste de contas' de parceiros de ações ilegais, entre outros. No entanto, o papel desempenhado por essa pessoa na situação de violência, como vítima ou agressor, não é tão claro ou imediato.

Com exceção daqueles que chegam custodiados por um policial e, portanto, já classificados como infratores, mas que certamente reivindicarão o papel de vítima. Portanto, a interação, o comportamento, sentimentos e reações da equipe profissional com esses sujeitos serão diferenciados (DESLANDES SF, 2001).

As falas a seguir descrevem os enfrentamentos dos profissionais entrevistados:

"Eu acho que um dos desafios é saber que muitos destes pacientes estão ali não como vítima de violência, mas sim porque de alguma maneira se colocaram naquela situação, muitas vezes por estarem envolvidos em crimes, brigas e et. A gente sabe disso e tem que ficar quieto" (E6).

"É difícil ter que aguentar esses indivíduos que cometem coisas ilícitas e, ainda, ouvir o discurso deles se vitimizando. Mas, não estamos ali pra julgar!" (E3).

Em contrapartida, alguns profissionais conseguem separar o senso de justiça de uma forma mais leve e humanizada, conforme as falas abaixo:

"O principal desafio que nós temos como profissionais de enfermagem para realizar assistência a indivíduos vítimas de violência por arma de fogo é exatamente não julgar o paciente na hora do cuidado, ficar buscando onde foi a etiologia do tiro. Tudo isto é um desafio, pois ainda cometemos o erro de julgamento" (E1).

"É difícil, mas temos que saber separar as coisas. Aqui eu sou profissional da enfermagem e não o advogado ou juiz para julgar o que o cliente fez, ainda mais quando sabemos que eles cometeram crimes graves" (E8).

Todo cidadão tem direito a uma assistência de saúde pública de qualidade e para tanto, em 2003 o Ministério da Saúde elaborou a Política Nacional de Humanização (PNH), também reconhecida como Humaniza-SUS.

Essa política objetiva aprimorar práticas de gestão e de atenção em saúde, garantido a qualidade da assistência, bem como a inclusão de usuários, trabalhadores e gestores reconhecendo a singularidade de cada ser (BRASIL, 2010).

Humanização em saúde está relacionada ao respeito, acolhimento e empatia, onde se leva em consideração as circunstâncias em que os sujeitos se encontram, seus valores, culturas e limitações sociais, éticas, educacionais e psíquicas.

O enfermeiro atua como promotor da humanização, pois acolhe e escuta todos que procuram os serviços, proporcionando respostas satisfatórias aos mesmos (LACERDA LX, et al., 2016). Outros relatos de profissionais reforçam o entendimento da necessidade de humanização a este perfil de paciente, sendo elas: 
"Estes pacientes muitas vezes estão no mundo do crime, mas não porque querem e sim, porque a criação os levou a isso. Tanto o pai ou mãe, aqueles que estavam como tutores e que deveriam conduzi-los a uma vida saudável, mas, foi totalmente ao contrário. Este é um cuidado que precisamos ter: não chegar acusando, dizendo que ele é um criminoso. Não podemos julgar, mas sim, buscar entender e fazer uma análise da vida do paciente. Buscar tratá-lo como qualquer ser humano que precisa ser respeitado dentro dessa situação. Eu digo que há insegurança e medo, mas ao mesmo tempo é prazeroso poder transmitir algo diferente para o ser humano" (E12).

"Acredito que a grande dificuldade em tratar estes pacientes é fazer com que eles entendam que nosso trabalho não é fazer julgamento de valores e atitudes. Demonstrar que nosso único objetivo é fazê-los saudáveis novamente. Muitas vezes são pessoas que temem até um simples toque ou gesto carinhoso. É preciso demonstrar o respeito que eles normalmente não encontram em pessoas que vivem fora do mundo que eles conhecem. Depois de alguns dias de convivência a grande maioria demonstra profundo agradecimento e respeito pelo nosso trabalho. Não são raras às vezes em que nos ajudam e apoiam no trato de um recém chegado rebelde e agressivo. Amo trabalhar com eles e perceber essa mudança. É preciso paciência, amor pelo trabalho e empatia pelo ser humano. Cada pessoa carrega consigo o resultado de suas experiências" (E13).

Portanto a abordagem ao cliente e seus familiares vítimas da violência urbana na assistência hospitalar deve ser realizada da melhor forma possível sem julgamentos e preconceitos. É fundamental levar em consideração a história de vida de cada indivíduo, bem como as questões socioculturais em que está inserido (OLIVEIRA MJS, et al., 2018). Atualmente, o cuidado prestado ao cliente hospitalizado está centrado na sua doença, gerando uma visão mecanicista do mesmo. Porém, o profissional de saúde deve priorizar as relações interpessoais estabelecidas por meio do vínculo e da escuta ativa, garantindo assim a assistência integral e humanizada deste indivíduo.

\section{CONCLUSÃO}

O presente estudo apontou os principais desafios enfrentados pelos profissionais de saúde na assistência aos indivíduos vítimas de violência por arma de fogo e branca. Como consequências destes enfrentamentos podemos destacar o baixo rendimento, desmotivação em exercer a profissão, medo, estresse, adoecimento físico e mental destes indivíduos. Diante dos fatos faz-se necessário a criação e implementação de políticas e estratégias a fim de prevenir situações de violência e melhorar as condições trabalhistas. Destaca-se que a escassez de fontes bibliográficas e a própria característica da invisibilidade do problema nas instituições de saúde são fatores limitadores, dificultando a ampliação de estudos com essa temática. Portanto, a presente pesquisa poderá contribuir para identificação, compreensão e enfrentamento do assunto em questão.

\section{REFERÊNCIAS}

1. ABREU FS, et al. Perfil epidemiológico das agressões por arma de fogo e arma branca no interior da Bahia. Rev Saúde Col, Bahia, 2014; 10(4): 361.

2. ANDOLHE R, et al. Estresse, coping e burnout da Equipe de Enfermagem de Unidades de Terapia Intensiva: fatores associados Rev Esc Enferm USP. São Paulo, 2015; 49(8).

3. ÁVILA J, et al. Conhecimento dos Enfermeiros frente ao abuso sexual. Avances En Enfermería, 2012; 30(2): 47-55.

4. BRASIL. Ministério da Saúde. Secretaria de Atenção à Saúde. Núcleo Técnico da Política Nacional de Humanização. Acolhimento nas práticas de produção de saúde / Ministério da Saúde, Secretaria de Atenção à Saúde, Núcleo Técnico da Política Nacional de Humanização. - 2. ed. 5. reimp. - Brasília: Editora do Ministério da Saúde, $2010 ; 44$.

5. CASTRO EAB, et al. Organização da atenção domiciliar com o Programa Melhor em Casa. Rev. Gaúcha Enferm. Porto Alegre, 2018; 39(1-20).

6. COFEN. Resolução № 240 de 30 de agosto de 2000: dispõe dos princípios fundamentais, aprova o código de ética dos profissionais de enfermagem e dá outras providências. BRASIL.

7. COSTA D, MARTINS M. Stress among nursing professionals: effects of the conflict on the group and on the physician's power. Revista da Escola de Enfermagem da USP, 2011; 45(5): 1191-1198. 
8. DESLANDES SF. A interação entre os profissionais e as vítimas de violência. In: Frágeis deuses: profissionais da emergência entre os danos da violência e a recriação da vida [online]. Rio de Janeiro: Editora FIOCRUZ, 2001. Antropologia \& saúde collection, pp. 119-148.

9. FERREIRA MJM, et al. Prevalência e fatores associados à violência no ambiente de trabalho em agentes de segurança penitenciária do sexo feminino no BRASIL. Ministério da Saúde. Secretaria de Atenção à Saúde. Política Nacional de Humanização da Atenção e Gestão do SUS. Programa de formação em saúde do trabalhador. Brasília, DF: Ministério da Saúde, 2017.

10. GIMÉNEZ MC, et al. Impact of work aspects on communication, emotional intelligence and empathy in nursing. Rev. Latino-Am. Enfermagem, 2019; 27.

11. IPEA - INSTITUTO DE PESQUISA ECONÔMICA APLICADA. Atlas da violência 2018. Rio de Janeiro: Ipea, 2018.

12. KESTENBERG CCF, et al. O estresse do trabalhador da enfermagem: um estudo em diferentes unidades de um hospital universitário. Rev. de Enferm. UERJ, Rio de Janeiro. 2015; 23(45-51).

13. LACERDA LX, et al. Humanização em um serviço de emergência: a vivência do projeto de extensão "acolher em saúde: posso ajudar?". In: $7^{\circ}$ Congresso Brasileiro de Extensão Universitária. Universidade Federal do Espírito Santo, 2016.

14. MACIEL PR, et al. Estudo descritivo do perfil das vítimas com ferimentos por projéteis de arma de fogo e dos custos assistenciais em um hospital da Rede Viva Sentinela. Epidemiologia e Serviços Saúde, Brasília, 2016; 25(3): 608.

15. MASLACH C, LEITER MP. Understanding the burnout experience: recent research and its implications for psychiatry. World Psychiatry [Internet]. 2016 [cited 2018 Mar 13].

16. MINAYO MCS. O desafio do conhecimento: Pesquisa qualitativa em saúde. São Paulo: Hucitec, $2014 ; 408$.

17. MOCELIN C, et al. O cuidado do idoso dependente no contexto familiar. Rev. Fun. Care Online, 2017; 9(4): $1034-9$.

18. OIT. Organización Internacional del Trabajo,Consejo Internacional de Enfermeras, Organización Mundial de la Salud, Internacional de Servicios Públicos. Directrices marco para afrontar la violencia laboral en el Sector de la Salud [Internet]. Ginebra: OIT; 2002.

19. OLIVEIRA EB, et al. Occupational stress and burnout in nurses of an emergency service: the organization of work. Rev Enferm UERJ, 2017; 25.

20. OLIVEIRA MJS, et al. A escuta ativa como estratégia de humanização da assistência em saúde. Rev Saúde e Desenvolvimento Humano, Canoas, 2018; 6(2).

21. RIBEIRO AP, et al. Lesões provocadas por armas de fogo atendidas em serviços de urgência e emergência brasileiros. Ciência \& Saúde Coletiva, 2017; 22(9): 2852.

22. SCARAMAL DA, et al. Violência física ocupacional em serviços de urgência e emergência hospitalares: percepções de trabalhadores de Enfermagem. REME - Rev Min Enferm, 2017; 21(102).

23. TAPIA CLV, et al. Papel do enfermeiro frente ao abuso sexual de crianças e adolescentes. Revista Saúde em Foco, Teresina, 2014; 1(1): 7, 93-102.

24. WHO. World Health Organization. 2018 Violência no trabalho: um tema para a cooperação em Recursos Humanos em Saúde, 2018. Acta paul. enferm. São Paulo, 2012; 25(2): 40-47.

25. VIDOTTI V, et al. Síndrome de burnout, estrés laboral y calidad de vida en trabajadores de enfermería. Enfermería Global, 2019; 18(3).

26. VASCONCELLOS IRR, et al. Violência ocupacional sofrida pelos profissionais de enfermagem do serviço de pronto atendimento hospitalar. Rev Gaúcha Enferm., Porto Alegre, 2012a; 33(2): 167-175.

27. VASCONCELLOS IRR, et al. Violência no trabalho diário de enfermagem hospitalar. Acta paul. enferm. São Paulo, $2012 b ; 25(2): 40-47$. 